\title{
Nanotechnology in medicine and healthcare: Possibilities, progress and problems
}

\author{
J Gardner, MScMed \\ Steve Biko Centre for Bioethics, Faculty of Health Sciences, University of Witwatersrand, Johannesburg, South Africa
}

Corresponding author: J Gardner (Jillian.Gardner@wits.ac.za)

\begin{abstract}
Nanotechnology or nanoscience covers the investigation, design, manipulation, precision placement, measurement, modelling or fabrication of matter, structures, devices and systems that exist at the nanoscale - essentially at the atomic and molecular size levels. Nanotechnology has the potential to change the way we address some of the world's most critical development problems. In 2005, the United Nations (UN) Millennium Project's Taskforce on Science, Technology and Innovation concluded that nanotechnology can contribute to the attainment of the Millennium Development Goals (MDGs), specifically, the goals to reduce child mortality, improve maternal mortality and combat HIV/ AIDS, malaria and other diseases. Health, specifically improved primary healthcare, is one of six focus areas highlighted in South Africa's National Nanotechnology Strategy (NNS), where nanotechnology can offer the most significant benefits for the country. Nanotechnology can revolutionise the practice of medicine and the delivery and accessibility of healthcare. However, despite the significant benefits of nanotechnology, there are problems that could prevent it from being widely accepted. The qualities that make nanotechnology so appealing are also those that give rise for concern. In particular, there are uncertainties about its potential impact on human health, the environment and societies in general, along with the concern that nanotechnology, much like genetic engineering or modification, is 'messing' with the building blocks of nature and is therefore, 'unnatural' even unethical. This article considers these concerns and concludes that there is nothing intrinsically good or bad about nanotechnology, but that its acceptability will depend largely on how it is used and introduced into society.
\end{abstract}

S Afri J BL 2015;8(2):50-53. DOI:10.7196/SAJBL.432

Nanotechnology or nanoscience covers the investigation, design, manipulation, precision placement, measurement, modelling or fabrication of matter, structures, devices and systems that exist at the nanoscale - essentially at the atomic and molecular size levels. ${ }^{[1,3]}$ The sizes of objects in nanotechnology are measured in units known as nanometres $(\mathrm{nm}){ }^{[3,4]}$ The size of one nanometre is invisible to both the human eye and most microscopes. ${ }^{[5]}$ On a comparative scale, if a marble were a nanometre, then one metre would be the size of the Earth, ${ }^{[6]}$ a sheet of paper about $100000 \mathrm{~nm}$ thick, ${ }^{[7]}$ and a human hair approximately $80000-100000 \mathrm{~nm}$ wide. ${ }^{[8]}$

Nanotechnology as defined by size, is, naturally, very broad, and allows for, among other things, the manipulation of materials on an atomic or molecular scale, thus enabling a new paradigm of science and technology which sees different fields of science and technologies converging at the nanoscale..$^{[9]}$ Nanotechnology is also known as a refining or enabling technology because of its capability to enhance existing technologies. ${ }^{[10]}$ It is not necessarily a distinct area of science but rather a radical redefinition of the combined power of science and technology. ${ }^{[1]}$ The application or use of nanotechnology in medicine and healthcare is known as nanomedicine. ${ }^{[12,13]}$

\section{Applications of nanotechnology in medicine and healthcare}

Nanotechnology has the potential to change the way we address some of the world's most critical development problems. In 2005, the United Nations (UN) Millennium Project's Taskforce on Science, Technology and Innovation concluded that nanotechnology can contribute to the attainment of the Millennium Development Goals (MDGs), specifically, the goals to reduce child mortality, improve maternal mortality and combat HIV/AIDS, malaria and other diseases. ${ }^{[2,11,14]}$ Health, specifically improved primary healthcare, is one of six focus areas highlighted in SA's National Nanotechnology Strategy (NNS), where nanotechnology can offer the most significant benefits for the country. ${ }^{[15]}$

Nanotechnology has a significant range of potential biomedical applications and is being used to develop nanodevices and structures to prevent, treat and monitor diseases. Some of the principal applications of nanomedicine are in the areas of diagnostics and testing, drug discovery, development and delivery, tissue engineering, medical instruments and devices and surgical treatments. ${ }^{[1,14,16]}$

\section{Disease screening and diagnosis}

Nanotechnology offers a multitude of options for detecting, diagnosing, monitoring and treatment of disease. For example, semiconducting nanocrystals called quantum dots can enhance biological imaging for medical diagnostics. ${ }^{[7,8,17,18]}$ When illuminated with ultraviolet light, they emit a wide spectrum of bright colours that can be used to locate and identify specific kinds of cells and biological activities. These crystals offer optical detection up to 1000 times better than conventional dyes used in many biological tests, such as MRIs, and render significantly more information. ${ }^{[7,8]}$ Scientists are exploring the use of nanotechnology in the development of portable point-of-care diagnostic kits, which would enable the rapid and accurate identification of multiple diseases simultaneously. ${ }^{[19]}$

\section{Drug development and delivery systems}

Nanotechnology can also be used to develop new forms of therapy and drug delivery systems. ${ }^{[20]}$ Through the use of nanotechnology, 
drugs can be delivered via nanovehicles to specific areas in the body with greater precision. ${ }^{[21]}$ The drugs can also be formulated so that the active ingredient better permeates cell membranes, reducing the required dose. ${ }^{[3,1]}$ Nanotechnology could therefore revolutionise drug delivery by overcoming challenges such as drug toxicity, how to sustain the release of drugs in the body and improving bioavailability - the amount of active ingredient per dose. Because of its potential to decrease drug administration time and minimise the side-effects of drugs, patient compliance could improve, thus contributing to the successful management and treatment of disease.

\section{Tissue engineering}

The tools and techniques of nanotechnology are also increasingly playing a role in advancing research in areas such as toxicogenomics, synthetic biology, regenerative medicine, and genetic modification. ${ }^{[1,10]}$ For instance, research is underway to use nanotechnology to spur the growth of nerve cells, e.g. in damaged spinal cord or brain cells. In one method, a nanostructured gel fills the space between existing cells and encourages new cells to grow. ${ }^{[7,8]}$ Another study is exploring the use of nanofibres to regenerate damaged spinal nerves. ${ }^{[7,8]}$

\section{Other applications}

Other applications of nanotechnology in medicine and healthcare include the use of nanoparticles in wound dressings and antiseptic coating for surgical implements. ${ }^{[1,14,16]}$

Nanotechnology is also likely to make novel forms of information management and medical communication possible e.g. patients might have medical information or records inserted under their skin, as is already done with radio frequency identification (RFID) tags. ${ }^{[1,11]}$

\section{Concerns about nanotechnology}

Nanotechnology can revolutionise the practice of medicine and the delivery and accessibility of healthcare. However, despite the significant benefits of nanotechnology, there are problems that could prevent it from being widely accepted. The qualities that make nanotechnology so appealing are also those that give rise for concern. In particular, there are uncertainties about its potential impact on human health, the environment and societies in general, along with the concern that nanotechnology, much like genetic engineering or modification, is 'messing' with the building blocks of nature and is therefore 'unnatural', even unethical.

\section{Concerns about human health, safety and rights}

Since a nanotechnology-based object can be so small, how can we tell where it is, or where it's going? Could engineered nanoparticles accumulate without our knowledge in the environment, our water supplies, crops, and bodies? What would the consequences of this be? ${ }^{[1]}$ Very little is known about the relationship between the exposure to engineered nanoparticles and health effects, in contrast with the large number of epidemiological studies on larger particles. ${ }^{[20]}$ The properties of nanoparticles are not governed by the same physical laws as larger particles, but by quantum mechanics. ${ }^{[22]}$ This means that the physical and chemical properties, e.g. colour, strength, chemical reactivity, solubility and toxicity can be quite different from those of larger particles of the same substance.
The extremely small size of nanoparticles also means that they are much more readily taken up by the human body than larger particles. They could cause overload on cells that ingest and destroy foreign matter, thereby triggering stress reactions that lead to inflammation and weaken the body's defence against other pathogens. Apart from what happens if non-degradable or slowly degradable nanoparticles accumulate in organs, another concern is their potential interaction with biological processes inside the body. Because of their large surface, nanoparticles on exposure to tissue and fluids will immediately absorb onto their surface some of the macromolecules they encounter. This may, for instance, affect the regulatory mechanisms of enzymes and other proteins. ${ }^{[20]}$

Although there is some research on the toxicity of nanotechnology and its effects on human health, such research is still rare. ${ }^{[1,2,20]}$ Data concerning the behaviour and toxicity of nanoparticles come mainly from studies on inhaled nanoparticles and from pharmaceutical studies, in which formulations involving nanoscale components are used to solve problems dealing with the insolubility of drug formulations and for drug delivery. ${ }^{[20]}$ Studies suggest that some nanoparticles may have unintended harmful consequences. For instance, inhaling airborne nanoparticles and nanofibres may lead to a number of pulmonary diseases, e.g. fibrosis, ${ }^{[23]}$ and some forms of carbon nanotubes could be as harmful as asbestos, which is a carcinogen, if inhaled in sufficient quantities. ${ }^{[24,25]}$

The large number of variables that influence behaviour and toxicity means that it is difficult to generalise about health risks associated with exposure to nanomaterials. Moreover, because the physical and chemical properties of nanoparticles can be quite different from those of larger particles of the same substance, risk assessment paradigms that have been developed for bulk materials may not be valid for nanoparticles and nanostructures. ${ }^{[1,26]}$ Therefore each new nanomaterial or application of nanotechnology must be assessed individually, on a case-by-case basis and all material properties must be taken into account. ${ }^{[1,20]}$ This suggests that different nanotechnology applications can have very different ethical profiles. For instance the application of nanotechnology in disease detection and treatment raises different issues to the application of nanotechnology in the development of biological weapons. To discuss the 'ethics of nanotechnology' in general is, therefore, not particularly productive. One bionanotechnology might be just, sustainable, and likely to contribute to human well-being, while another might be unjust, unsustainable, reckless, and unnecessary. Nevertheless nanotechnology, due to its broad applications in medicine and healthcare is implicated in a broad range of bioethical issues including informed consent, justice, and access to healthcare, privacy of medical information, end-of product disposal and human subjects' protections. ${ }^{[1]}$

Nanomedicine will likely transform the organisation and practice of medicine and healthcare. In the field of medicine and healthcare, advances in nanotechnology can be combined with other technologies, including information technology and biotechnology, increasing nanotechnology's potential to displace health measures and systems where regulation has been worked out over many years. One example is the development of computer-controlled molecular tools that may not require the direct intervention of a medical practitioner. ${ }^{[3]}$ Some functions could therefore be relegated to other staff; as has been done, e.g. in the case of permitting lay counsellors 
to conduct HIV testing and counselling or enabling registered nurses to test for and prescribe treatment for HIV independently in SA. In the context of research the invisible nature of nanotechnology makes it easier to 'hide' nanotech products, and to invade privacy or carry out procedures that require consent, without the patient's knowledge. This may be particularly pertinent with regard to clinical trials of nanodrugs carried out in developing countries. ${ }^{[3]}$

\section{Concerns about the impact on the environment}

Although there are very few published data on the effects of nanoparticles on environmental species, ${ }^{[27]}$ it is reasonable to assume that observations can be extrapolated to environmental species. There is, for instance, evidence that bacteriostatic silver nanoparticles used in socks to reduce foot odour are being released in the wash. ${ }^{[28]}$ These particles are then flushed into the waste water stream and may destroy bacteria which are critical components of natural ecosystems, farms and waste treatment processes. ${ }^{[29]}$ This perhaps explains why a report by the UK Royal Society and Royal Academy of Engineering recommends that nanoparticles and nanotubes be treated as hazardous waste..$^{[4]}$ Even if nanotechnology is perceived to be no more than small mutations, it is recognised, from an industrial ecology perspective, ${ }^{[30]}$ that similarly to most large-scale production the production of nanomaterials requires energy, $^{[31,32]}$ as well as feedstock chemicals ${ }^{[33]}$ some of which are toxic to humans and other organisms. Nanomanufacturing methods therefore raise the question of whether or not the benefits of using nanotechnology as an alternative to existing technologies really outweigh the impacts of producing nanomaterials, with reference to energy requirements, environmental impacts and disposalrelated costs and risks. ${ }^{[2]}$

\section{Justice-related concerns}

Critics argue that investment in nanotechnologies by resource-poor countries is a waste of money, since most people in those countries don't even have access to basic healthcare services. ${ }^{[34]}$ Moreover, even if developed, how accessible will this type of technology be to the average citizen? Will it be limited to specific socioeconomic groups that can afford it or will it be available to everyone? If nanotechnology does not seek to benefit wider society by responding to social needs it could widen the gap between rich and poor people and countries because of their different capacities to develop and exploit nanotechnologies. ${ }^{[11]}$

\section{Concerns about the unnaturalness of nanotechnology}

Nanotechnology enables scientists to deconstruct and remake the world ('nature') from the atom up, using atomic level manipulation to transform and construct a wide range of new materials, devices, living organisms and technological systems. Critics may therefore argue that it is unnatural, hence immoral. Such arguments, however, simply equate the ethical with what is natural, and fail to appreciate that humans are themselves part of nature, who have and continue to, often, interfere with nature. The natural-unnatural division is not in itself of intrinsic moral significance, otherwise much of medicine, for instance, would be immoral. Humans intervene in nature all the time and usually for good moral reasons so there cannot be something inherently immoral about nanotechnology. Moreover, some people may see the responsible exercise of scientific skills as being the employment of God-given abilities.

As with other health technologies, there is nothing intrinsically good or bad about nanotechnology. It will depend on how it is used. An important component of responsible research and development (R\&D) of nanotechnology is the consideration of the ethical, legal and social implications. How research and applications are introduced into society; how transparent decisions are; how sensitive and responsive policies are to the needs and perceptions of the range of stakeholders and how ethical, legal and social issues are addressed will determine public trust and future innovation driven by nanotechnology. The successful introduction of a new technology requires careful attention to the interactions between the technology and society. ${ }^{[35]}$ Negative public opinion can obstruct the application of technological advances. ${ }^{[36]}$ The public backlash against genetically modified foods effectively stalled a new industry in many parts of the world. ${ }^{[37]}$ The scientific community should continually engage the public in proactive dialogue to promote awareness and informed decision-making about the safety, ethics and regulation of nanotechnology. ${ }^{[38,39]}$

\section{Conclusion}

Despite the significant benefits that the application of nanotechnology in medicine and healthcare promises, there are concerns about its future implications. Nanotechnology may be able to create many new materials and devices with a vast range of applications that could enhance human welfare. On the other hand, what is technically possible and what is ethically appropriate is a matter of heated debate. Nanotechnology raises many of the same issues as genetically modified foods. ${ }^{[34]}$ These include concerns about the toxicity and environmental impact of nanomaterials, and their potential effects on global economics - issues which threaten to hamper the successful implementation and uptake of nanotechnology. How nanotechnology research and development and the marketing of products might impact human living conditions as well as beliefs, values and social relationships is, as yet, an unanswered question. Therefore the unknown and potentially substantial harms and benefits it represents to social, cultural, and material life warrants careful ethical reflection. Research funded by public money must benefit society. Health policies are not just about curing disease, but about keeping people healthy. In developing countries the main health problems have socioeconomic and lifestyle causes, which cannot be solved by technology alone, however sophisticated it may be. In developing countries nanotechnology for health should therefore improve living conditions, not just treat disease. ${ }^{[40]}$

There are considerable difficulties in assessing the health, environmental and ecological impact of nanotechnology because of uncertainties and knowledge gaps, largely due to the natural complexity of ecological cycles, and the impossibility of directly experimenting with the natural environment. Knowledge about the hazard and exposure risk of nanoparticles to the ecology is therefore slim..$^{[41]}$ Therefore the proper question for regulators and policymakers to ask of nanotechnology is not 'Is it safe?' but rather,

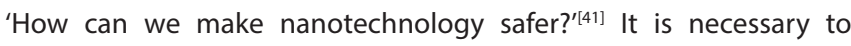
identify the acceptable risk threshold and to balance the potential harms while respecting the values at stake. ${ }^{[1]}$ 


\section{References}

1. Michelson ES, Sandler R, Rejeski D. Nanotechnology. In: Crowley M ed. From Birth to Death and Bench to Clinic: The Hastings Center Bioethics Briefing Book for Journalists, Policy Makers, and Campaigns. Garrison, NY: The Hastings Center. 2008:111-116

2. Musee N, Brent AC, Ashton PJ. A South African research agenda to investigate the potential environmental health and safety risks of nanotechnology. S Afr J Sc 2010;106:3-4. [http://dx.doi.org/10.4102/sajs.v106i3/4.159]

3. Shetty P. Nanotechnology for health: Facts and figures. London: Science and Development Network (SciDev.Net); 2010. http://www.scidev.net/global/health/ feature/nanotechnology-for-health-facts-and-figures (accessed 2 November 2015).

4. The Royal Society and Royal Academy of Engineering. Nanoscience and Nanotechnologies: Opportunities and uncertainties. London. The Royal Society and Royal Academy of Engineering 2004:13-57.

5. Wetter K. Big continent and tiny technology: Nanotechnology and Africa. Pambazuka News, 2010;499. http://www.pambazuka.net/en/category/features/67525 (accessed 2 November 2015)

6. Fleming AJ, Leang KK. Design, Modeling and Control of Nanopositioning. Switzerland: Springer International Publishing. 2004:1-15.

7. United States Government. United States National Nanotechnology Initiative. Frequently Asked Questions. Arlington: United States Nanotechnology Initiative 2015. http://www.nano.gov/nanotech-101/nanotechnology-facts. (accessed 2 November 2015).

8. United States Government. United States National Nanotechnology Initiative. Size of the nanoscale. Arlington: United States Nanotechnology Initiative, 2015 http://www.nano.gov/nanotech-101/what/nano-size. (accessed 2 November 2015).

9. Saini R, Saini S, Sharma S. Nanotechnology: The Future Medicine. J Cutan Aesthet Surg 2010;3(1):32-33. [http://dx.doi.org/10.4103/0974-2077.63301]

10. South African Agency for Science and Technology Advancement Nanotechnology and Health. Pretoria: South African Agency for Science and Technology Advancement. February 2011. Available at http://www.npep.co.za/ pdfs/articles-and-factsheets/Health/fact\%20sheet.pdf. (accessed 2 November 2015)

11. Gardner J, Dhai A. Nanotechnology and Water: Ethical and Regulatory Considerations. In: Ajay Kumar Mishra, ed. Application of Nanotechnology in Water Research. Massachusetts. Scrivener Publishing LLC, 2014:1-20.

12. Freitas RA Jnr. What is Nanomedicine? Nanomedicine: Nanotech Biol Med 2005;1(1):2-9. [http://dx.doi.org/10.1016/j.nano2004.11.003]

13. Moein Moghimi S, Christy Hunter A, Clifford Murray J. Nanomedicine: Current status and future prospects. The FASEB Journal 2005;19(3):311-330. [http:// dx.doi.org/10.1096/fi.04-2747rev]

14. Salamanca-Buentello F, Persad DL, Court EB, Martin DK, Daar AS, Singer PA. Nanotechnology and the developing world. PLoS Med 2005;2(5):e97. [http:// dx.doi.org/10.1371/journal.pmed.0020097]

15. Republic of South Africa. Department of Science and Technology (DST). The national nanotechnology strategy. Pretoria: Government Gazette, 2007. http:// www.dst.gov.za/publications-policies/strategies-reports/reports/Nanotech.pdf. (accessed 2 November 2015)

16. Duncan R. The dawning era of polymer therapeutics. Nat Rev Drug Discov 2003;2(5):347-360 [http://dx.doi.org/10.1038/nrd1088]

17. Maclurcan DC. Nanotechnology and developing countries Part 1: What possibilities? Online Journal of Nanotechnology 2005;1. [http://dx.doi. org/10.2240/azojono0103]

18. Mathuria JP. Nanoparticles in tuberculosis diagnosis, treatment and prevention A hope for the future. Dig J Nanomater Biostruct 2009:4(2):309-312.

19. Yen C-W, de Puig H, Tam JO, et al. Multicolored silver nanoparticles for multiplexed disease diagnostics: Distinguishing dengue, yellow fever, and Ebola viruses. Lab on a Chip 2015;15(7):1638-1641). [http://dx.doi.org/10.1039/c5lc00055f]
20. Scientific Committee on Emerging and Newly Identified Health Risks (SCENIHR). The appropriateness of existing methodologies to assess the potential risks associated with engineered and adventitious products of nanotechnologies. Luxembourg SCHENIHR, 2006. http://ec.europa.eu/health/ph_risk/committees/04_scenihr/docs/ scenihr_o_003b.pdf. (accessed 2 November 2015).

21. Mamo T, Moseman EA, Kolishetti N, et al. Emerging nanotechnology approaches for HIV/AIDS treatment and prevention. Nanomedicine 2010;5(2):269-285. [http://dx.doi.org/10.2217/nnm.10.1]

22. Cameron N, Mitchell E. Nanoscale: Issues and Perspectives for the Nano Century. New Jersey: John Wiley \& Sons Inc. 2007:74.

23. Byrne JD, Baugh JA. The significance of nanoparticle-induced pulmonary fibrosis Mcgill J Med 2008;11(1):43-50.

24. Liu X, Vinson D, Abt D, Hurt RH, Rand DM. Differential toxicity of carbon nanomaterials in drosophila: Larval dietary uptake is benign, but adult exposure causes locomotor impairment and mortality. Environ Sci Techno 2009;43(16): 6357-6363. [http://dx.doi.org/10.1021/es901079z]

25. Kipen M, Laskin D. Smaller is not always better: Nanotechnology yields nanotoxicology. Am J Physiol Lung Cell Mol Physiol 2005;289(5):L696-L697. [http://dx.doi.org/10.1152/ajplung.00277.2005]

26. Hunt G, Mehta M. Nanotechnology: Risk, ethics, law. London: Earthscan. 2006; 3-45.

27. Colvin VL. The potential environmental impact of engineered nanomaterials. Nat Biotechnol 2003;21(1):1166-1170. [http://dx.doi.org/10.1038/nbt875]

28. Lubick N. Silver socks have cloudy lining. Eviron Sci Technol 2008:42(11):3910.

29. Murray RGE. A perspective on S-layer research. In: Beveridge TJ, Koval SF, eds. Advances in Bacterial Paracrystalline Surface Layers. USA: Springer. 1993:3-9. [http://dx.doi.org/10.1007/978-1-4757-9032-0]

30. Brent AC, Oelofse S, Godfrey L. Advancing the concepts of industrial ecology in South African institutions. S Afr J Sci 2008;104(1/2):9-12.

31. Khanna V, Bakshi BR, Lee LJ. Carbon nanofiber production: Life cycle energy consumption and environmental impact. J Ind Ecol 2008;12(3):394-410. [http:// dx.doi.org/10.1111/j.1530-9290.2008.00052.x

32. Kushnir D, Sandén BA. Energy requirements of carbon nanoparticle production. J Ind Ecol 2008;12(3):360-375. [http://dx.doi.org/10.1111/j.15309290.2008.00057.x]

33. Wardak A, Gorman ME, Swami N, Deshpande S. Identification of risks in the life cycle of nanotechnology-based products. J Ind Ecol 2008;12(3):435-448. [http:// dx.doi.org/10.1111/j.1530-9290.2008.00029.x]

34. Court E, Daar AS, Martin E, Acharya T, Singer PA. Will Prince Charles et al. diminish the opportunities of developing countries in nanotechnology? Nanotechweb 2004; Jan 28. http://nanotechweb.org/cws/article/indepth/18909. (accessed 2 November 2015).

35. Keller K. Nanotechnology and society. J Nanoparticle Res 2007;9(1):5-10. [http:// dx.doi.org/10.1007/s11051-006-9193-3]

36. Service RF. Nanotechnology grows up. Science 2004;304(5678):1732-1734 [http://dx.doi.org/10.1126/science.304.5678.1732]

37. Macoubrie J. Nanotechnology: Public concerns, reasoning and trust in government. Pub Understand Sci 2006;15(2):221-241. [http://dx.doi.org/10.1177/0963662506056993]

38. Arnall AH. Future Technologies, Today's Choices: Nanotechnology, Artificial Intelligence and Robotics - A Technical, Political and Institutional Map of Emerging Technologies. London: Greenpeace Environmental Trust 2003. http:// www.greenpeace.org.uk/MultimediaFiles/Live/FullReport/5886.pdf. (accessed 2 November 2015)

39. Rogers-Hayden T,Pidgeon N.Moving engagement"upstream"? Nanotechnologies and the Royal Society and Royal Academy of Engineering's inquiry. Pub Understand Sci 2007;16(3):345-364. [http://dx.doi.org/10.1177/0963662506076141]

40. Foladori G. Nanotechnology for health is not just about disease. London: Sci Dev Network, 2010. http://www.scidev.net/en/health/nanotechnology-for-health (accessed 2 November 2015).

41. UNESCO. The Ethics and Politics of Nanotechnology. Paris: UNESCO, 2006. http:// unesdoc.unesco.org/images/0014/001459/145951e.pdf. (accessed 2 November 2015). 